\title{
Small intestinal neuroendocrine tumours and fibrosis: an entangled conundrum
}

\author{
Anela Blažević, Johannes Hofland, Leo J Hofland, Richard A Feelders and Wouter W de Herder \\ Department of Internal Medicine, Sector Endocrinology, ENETS Centre of Excellence, Erasmus University Medical Center (Erasmus MC) and Erasmus MC \\ Cancer Institute, Rotterdam, Netherlands
}

Correspondence should be addressed to A Blažević: a.blazevic.1@erasmusmc.nl

\begin{abstract}
Small intestinal neuroendocrine tumours (SI-NETs) are neoplasms characterized by their ability to secrete biogenic amines and peptides. These cause distinct clinical pathology including carcinoid syndrome, marked by diarrhoea and flushing, as well as fibrosis, notably mesenteric fibrosis. Mesenteric fibrosis often results in significant morbidity by causing intestinal obstruction, oedema and ischaemia. Although advancements have been made to alleviate symptoms of carcinoid syndrome and prolong the survival of patients with SI-NETs, therapeutic options for patients with mesenteric fibrosis are still limited. As improved insight in the complex pathogenesis of mesenteric fibrosis is key to the development of new therapies, we evaluated the literature for known and putative mediators of fibrosis in SI-NETs. In this review, we discuss the tumour microenvironment, growth factors and signalling pathways involved in the complex process of fibrosis development and tumour progression in SI-NETs, in order to elucidate potential new avenues for scientific research and therapies to improve the management of patients suffering from the complications of mesenteric fibrosis.
\end{abstract}

\author{
Key Words \\ - neuroendocrine tumour \\ - fibrosis \\ - growth factors \\ - targeted therapy \\ tumour microenvironment
}

\section{Introduction}

Small intestinal neuroendocrine tumours (SI-NETs) are rare and mostly slow-growing neoplasms originating from the enterochromaffin (EC) cells of the intestine (de Herder 2005, Yao et al. 2008). EC cells are chemo- and mechanosensory cells that integrate signals from the bowel content and peristalsis and communicate with the neural sensory system in order to control gut motility, secretion and visceral sensation (Linan-Rico et al. 2016, Bellono et al. 2017). Retention of the ability of EC cells to secrete amines and peptides can cause distinct hormonal syndromes in SI-NETs (de Herder 2005, Yao et al. 2008). Carcinoid syndrome, marked by diarrhoea and flushing, is the most established of these hormonal syndromes and is caused by release of 5-hydroxytryptamine (serotonin), tachykinins and bradykinins and many other mediators (de Herder 2005, Halperin et al. 2017).
Another hallmark of SI-NETs is the ability to induce fibrosis. The fibrosis can occur around the tumour or at distant sites (Modlin et al. 2004, Niederle et al. 2016). Endocardial fibrosis of the right heart valves, known as carcinoid heart disease, is the most frequent distant fibrotic complication that occurs in 20-30\% of SI-NET patients. Carcinoid heart disease is associated with metastatic disease and carcinoid syndrome, suggesting an etiological role for circulating tumour-secreted factors (Modlin et al. 2004, de Herder 2005, Niederle et al. 2016). However, in this review, we will focus on local fibrotic complications, of which mesenteric fibrosis (MF) is most notable and occurs in up to 50\% of SI-NET patients (Rodriguez Laval et al. 2017). It is caused by a metastatic lesion circumscribed by an extensive fibrotic reaction in the mesentery 


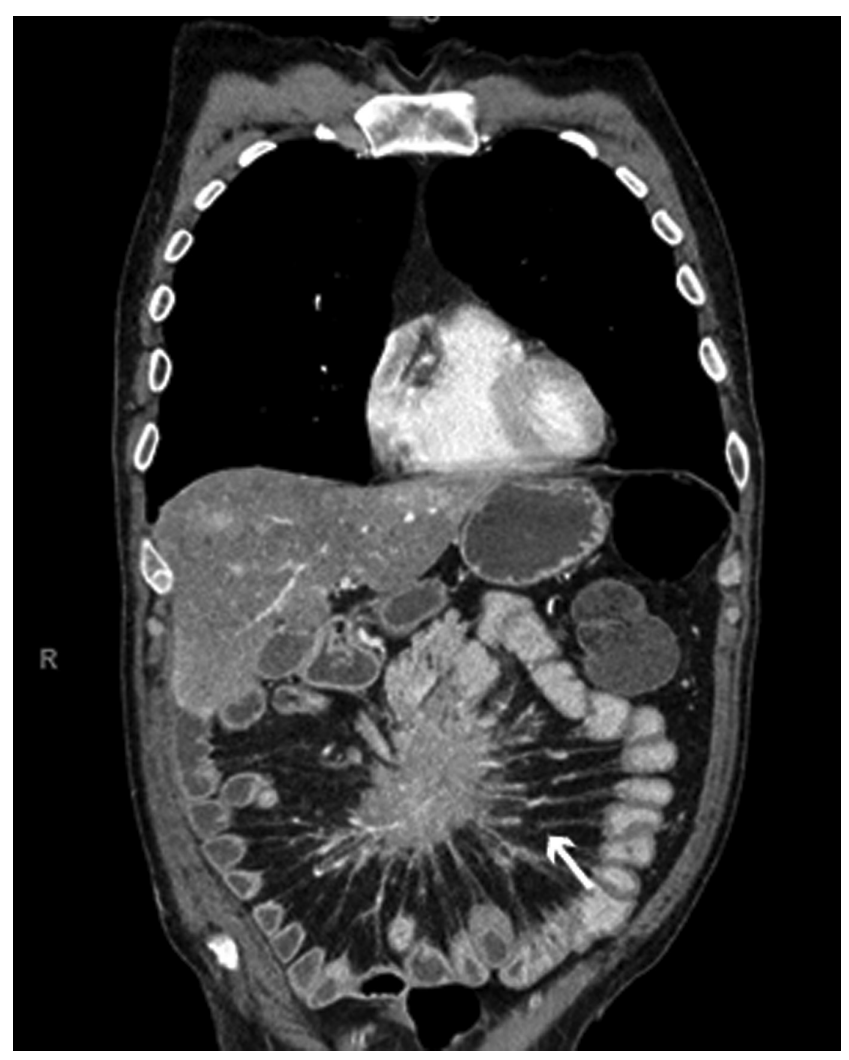

Figure 1

Coronal CT-image showing typical mesenteric fibrosis as radiating strands of soft-tissue (arrow) surrounding a metastatic mesenteric mass.

(Fig. 1). MF leads in a significant percentage of patients to intestinal obstruction, oedema and ischaemia, which causes abdominal pain, cachexia and often necessitates surgery (Makridis et al. 1990, Öhrvall et al. 2000, Druce et al. 2010). To date, surgery is the only treatment option for patients with complaints due to MF (Makridis et al. 1990, Modlin et al. 2004). Because survival of patients improved since the development of targeted and more effective therapies for carcinoid syndrome and tumour growth control, there is increased need for advancements in treatment options for MF (Niederle et al. 2016, Pavel et al. 2016). As improved knowledge of the pathogenesis of fibrosis is key to the development of new therapies, we assessed in this review literature on putative mediators of MF in SI-NETs and treatments targeting these factors.

\section{Methods}

MEDLINE, EMBASE, Web of Science, Cochrane CENTRAL and Google Scholar (first 100 results) were systematically searched in February 2017. The search strategy was designed to search highly sensitive for studies on fibrosis in neuroendocrine tumours. The search strategy is provided in the Supplementary Data (see section on supplementary data given at the end of this article). The reference lists of included studies and relevant reviews were assessed to identify additional articles.

\section{Results}

\section{Tumour microenvironment (TME)}

Tissue homeostasis is maintained by intricate interactions between cells and their microenvironment. Bidirectional communication between SI-NET cells and other components of the TME alters the composition of the microenvironment that can become profibrotic and tumourigenic. Therefore, understanding the TME is crucial in order to decipher how SI-NETs induce fibrosis (Quail \& Joyce 2013). Over the last decades, cancer research has been increasingly focused on the TME and found many commonalities with chronic wound healing that results in fibrosis (Rybinski et al. 2014). The local microenvironment of cancer cells is commonly referred to as 'reactive stroma'. This reactive tumour stroma consists of immune cells, fibroblasts, capillaries, basement membrane and extracellular matrix (ECM). The TME is crucial for tumour growth, invasion and metastasis, with both cancer-promoting as cancer-restraining actions of most components and is known to differ between cancer types (Quail \& Joyce 2013). The tumour stroma of SI-NETs differs from other cancers with a characteristic desmoplastic reaction and limited leukocytic infiltration (Chaudhry et al. 1992, Pantongrag-Brown et al. 1995, Zhang et al. 2004). Therefore, the pathobiological processes in the SI-NET TME differ from other cancer types. Moreover, because of the commonalities between pathways involved in development of fibrosis and cancer progression, insight gained in the distinct effects of different TME components in SI-NETs can result both in effective anticancer as well as antifibrotic treatment.

Fibroblasts are the dominant cellular component of tumour stroma, next to tumour cells. The majority of these fibroblasts have a modified phenotype, similar to fibroblasts during wound healing. This activated phenotype of cancer-associated fibroblasts (CAFs) is identified by expression of $\alpha$-smooth muscle actin $(\alpha \mathrm{SMA})$. In contrast to quiescent fibroblasts, CAFs are able to proliferate, produce growth factors and ECM (Kalluri 2016). Compared to other neuroendocrine tumours, SI-NETs have a high expression of $\alpha \mathrm{SMA}$ in the fibroblast component of the TME both in primary 
tumours and metastases (Facco et al. 1998, Kidd et al. 2007c, Cunningham et al. 2010). Further evidence on the presence of synthetic fibroblasts in SI-NETs was detected in primary cultures in which cells from the tumour stroma developed the typical stellate shape of CAFs and increased growth factor transcription after stimulation with transforming growth factor beta 1 (TGF $\beta 1$, see later) (Kidd et al. 2007c). This suggests that also in SI-NETs, CAFs are important regulators of fibrotic stromal programmes.

Immune cells are another important constituent of the TME, and dysregulation of the local immune system and inflammatory response is implicated in both tumourigenesis and development of fibrosis (Wynn 2008, Rybinski et al. 2014). A major component of the leukocytic infiltrate in the TME is the tumour-associated macrophages (TAMs) (Quail \& Joyce 2013, Rybinski et al. 2014). TAMs have in general a tumour-promoting role, suppress the adaptive immune system and stimulate fibrosis by secretion of profibrotic factors such as TGF $\beta$ (Mantovani et al. 2008, Quail \& Joyce 2013). In SI-NETs, there is less leukocytic infiltration compared to other cancers (Funa et al. 1990). The sparsely found leukocytes are mostly macrophages, as identified by Leu M5 antibody staining (Funa et al. 1990, Chaudhry et al. 1992). These macrophages also stained strongly for TGF $\beta$ and plateletderived growth factor (PDGF), suggesting a polarized, TAMphenotype, which is associated with cancer-promoting effects (Chaudhry et al. 1992, Mantovani et al. 2008).

The final component of the TME to be discussed is the extracellular matrix (ECM). This tissue compartment provides structural support and provides biochemical and biomechanical cues necessary for tissue homeostasis. The ECM consists of a panoply of proteins and polysaccharides. The specific concentration of these different matrix components controls the biomechanical properties of the ECM. Remodelling and a shift in the composition of the ECM are shown both in fibrotic and neoplastic diseases (Cox \& Erler 2011). As the EC cell and BON1 cells, a pancreatic NET cell line, are mechanosensitive and mechanical stress has been shown to induce release of signalling molecules such as serotonin in these cells, changes in ECM composition might influence tumour functionality in SI-NETs by biochemical and biomechanical signals (Linan-Rico et al. 2016). Unfortunately, little is known about the specific composition and changes in the ECM of SI-NETs. In fibrotic diseases, inappropriate activation of fibroblasts results in increased collagen production (Cox \& Erler 2011). Kidd and colleagues have shown the presence of collagen III surrounding CAFs in SI-NETs, further confirming an activated, synthetic phenotype
(Kidd et al. 2007c). Next to collagen, the ECM can contain various proteoglycans such as heparan and chondroitin sulfate (Cox \& Erler 2011). Analysis of transcription levels of these proteoglycans in NETs showed changes during disease progression; however, their role in tumour progression and development of fibrosis in SI-NETs is still elusive (García-Suárez et al. 2014).

\section{Profibrotic growth factors}

As mentioned earlier, deregulation of signals changes the microenvironment resulting in tumour progression and fibrosis. Therefore, along with understanding the TME, it is important to investigate the signalling molecules that mediate these changes. These molecules, which regulate cell-fate processes such as proliferation, differentiation and migration, are commonly referred to as growth factors (Witsch et al. 2010). In this next part, growth factors with known profibrotic effects will be discussed, in order to further elucidate the pathobiology of fibrosis in SI-NETs (Fig. 2).

\section{Serotonin}

Serotonin is a biogenic amine that can act as a neurotransmitter, hormone or growth factor (MohammadZadeh et al. 2008). As a high level of serotonin secretion characterizes functional SI-NETs, this was considered as the causal agent of fibrosis (Modlin et al. 2004). Serotonin controls various physiological functions and is known to have a mitogenic effect on a variety of cells (Mann \& Oakley 2013). The ability of serotonin to have a wide array of effects is attributed to its diverse receptor system. It consists of seven families of 5-HT receptors of which six are G-protein coupled. As most families exhibit heterogeneity in form and function, they are further divided in subtypes as $5-\mathrm{HT}_{1 \mathrm{~A}}$ and $5-\mathrm{HT}_{1 \mathrm{~b}}$, etc. The EC cells of the intestine are the main source of peripheral serotonin (Mohammad-Zadeh et al. 2008). As SI-NETs originated from these EC cells, serotonin immunohistochemistry (IHC) is positive in $>85 \%$ of the SI-NETs and can be used as a marker for intestinal origin of neuroendocrine tumours (Yang et al. 1983, Krishnamurthy \& Dayal 1997, Facco et al. 1998, Niederle et al. 2016). Furthermore, the majority of patients with SI-NET have increased urinary excretion of 5-hydroxyindoleactic acid (5-HIAA), the main metabolite of serotonin (Niederle et al. 2016, Zandee et al . 2016, Rodriguez Laval et al. 2017). Also, increased 5-HIAA excretion is associated with the presence of MF (Rodriguez Laval et al. 2017). A causal link between serotonin and fibrosis is furthermore suggested by the association 


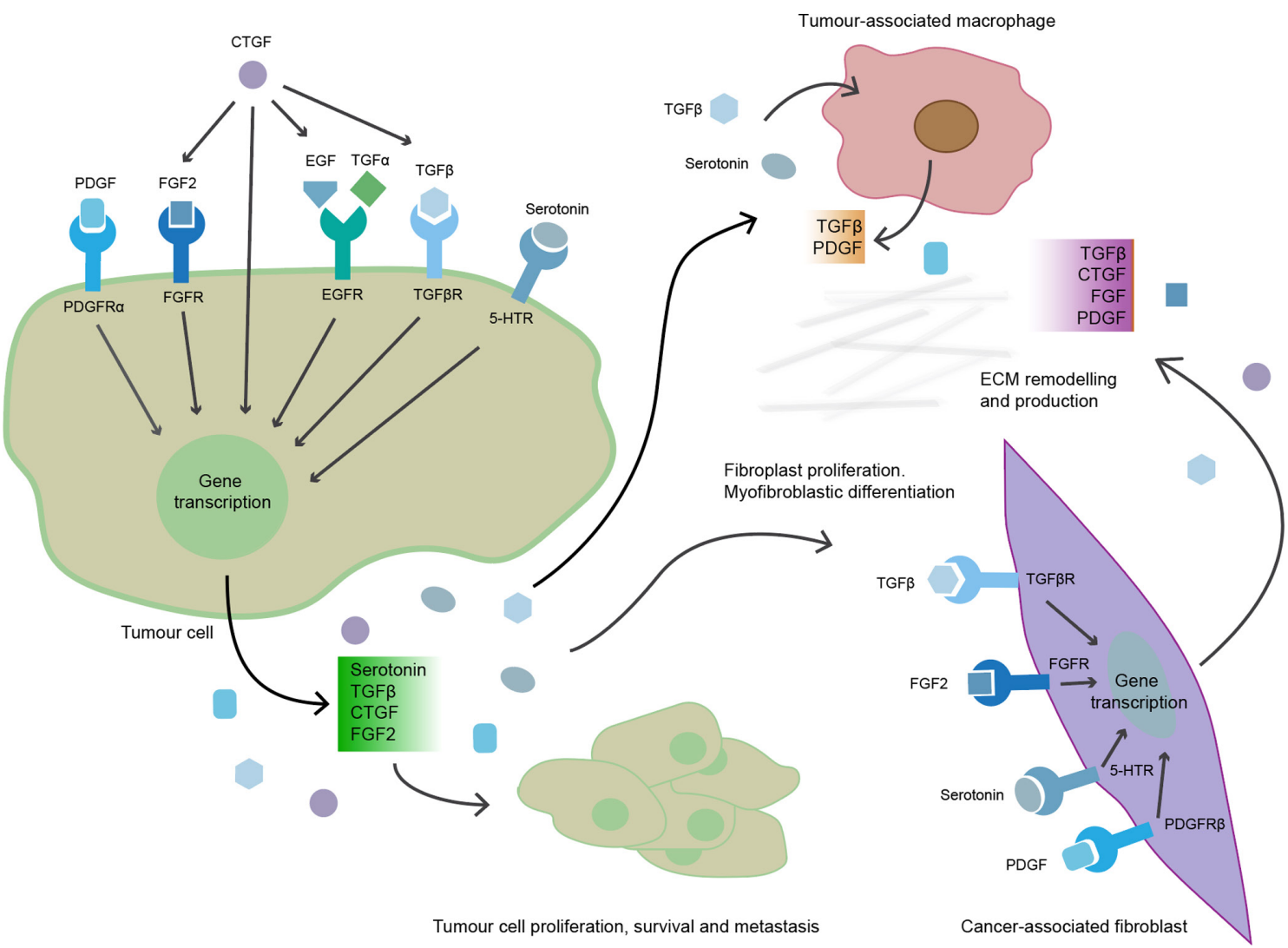

\section{Figure 2}

Development of mesenteric fibrosis in SI-NETs. Interactions of profibrotic growth factors within the tumour microenvironment, which consists among others of tumour cells, fibroblasts, immune cells and extracellular matrix (ECM). 5-HTR, serotonin receptor; CTGF, connective tissue growth factor; EGF, epidermal growth factor; EGFR, epidermal growth factor receptor; FGF2, basic fibroblast growth factor; FGFR, fibroblast growth factor receptor; PDGF, platelet-derived growth factor; PDGFR, platelet-derived growth factor receptor; TGF $\alpha$, transforming growth factor alpha; TGF $\beta$, transforming growth factor beta; TGF $\beta$, transforming growth factor beta receptor.

of fibrotic complications with drugs targeting $5-\mathrm{HT}_{2 \mathrm{~B}}$ receptor such as methysergide, an anti-migraine drug (Mann \& Oakley 2013). In KRJ-I cells, a small intestinal EC cell-derived NET cell line, serotonin stimulation resulted in increased proliferation of tumour cells, which could be reversed by ketanserin, a $5-\mathrm{HT}_{2 \mathrm{~A} / \mathrm{C}}$ receptor antagonist (Kidd et al. 2007a, Drozdov et al. 2009). Also, a 5-HT $2 \mathrm{~B}$ receptor antagonist resulted in decreased viability of KRJ-I cells and reduced secretion of serotonin and the profibrotic growth factors TGF $\beta 1$, connective tissue factor (CTGF) and basic fibroblast growth factor (FGF2) by these cells (Svejda et al. 2010).

Furthermore, fibroblasts are shown to express 5-HT receptors and in other fibrotic diseases, such as pulmonary and liver fibrosis, the direct proliferative effect of serotonin on fibroblasts seems to be mediated via specific 5 -HT receptors, namely the $5-\mathrm{HT}_{1 \mathrm{a} / \mathrm{b}}, 5-\mathrm{HT}_{2 \mathrm{~A}}$ and 5-HT $\mathrm{H}_{2 \mathrm{~b}}$ receptors (Mann \& Oakley 2013). These results point to serotonin as the main driver of fibrosis. However, a direct proliferative effect of serotonin on SI-NET CAFs has not been shown (Beauchamp et al. 1991, Svejda et al. 2010). Also, MF is not exclusively found in patients with elevated 5-HIAA excretion (Rodriguez Laval et al. 2017). In combination with increased knowledge of the profibrotic effects of growth factors that might be therapeutically targeted, this resulted in a shift of focus to possible other etiological agents of MF (Rybinski et al. 2014).

\section{Transforming growth factor beta (TGF $\beta$ ) family}

The TGF $\beta$ family of cytokines is a pivotal regulator of proliferative and profibrotic processes. The family consists of three isoforms (TGF $\beta 1$, TGF $\beta 2$ and TGF $\beta 3$ ); however, the extended superfamily includes many more proteins such as bone morfogenetic proteins (BMPs). TGF $\beta$ binds exclusively to TGF $\beta$ type 1 receptor (TGF $\beta$ R 1 ) and type 2 receptor (TGF $\beta$ R2). After binding to these receptors, the cellular effects are mediated viaSMAD pathway (Witsch etal. 2010, Massague 2012). TGF $\beta$ signalling has a dual role with on the one hand antitumourigenic and antiproliferative 
effects in physiological and early neoplastic conditions, and on the other hand, protumourigenic effects such as proliferation and invasion in later stages of malignant disease (Massague 2012). Also, it stimulates stromal cells to induce myofibroblastic differentiation and altered ECM production. Once differentiated to myofibroblast, these cells secrete TGF $\beta$ creating a self-sustained, profibrotic feedback loop (Witsch et al. 2010). Due to its profibrotic and protumourigenic effects, TGF $\beta$ is one of the most extensively studied growth factors in SI-NETs.

It has been shown that BON1 cells and tissue specimens of SI-NETs express the transcripts of all three TGF $\beta$ s ( $\beta 1, \beta 2$ and $\beta 3$ ) and both receptors (TGF $\beta$ R1 and TGFßR2) (Beauchamp et al. 1991, Chaudhry et al. 1994, Wulbrand et al. 1998, Wimmel et al. 2003). The expression of TGF $\beta$ isoforms differs between tissue components with all three isoforms being present in tumour tissue, but only TGF $\beta 2$ showed strong IHC staining in stroma (Chaudhry $\&$ Oberg 1993). However, no significant correlation was found with MF and expression levels of TGF $\beta 1$ and TGF $\beta 3$ in SI-NET tumour tissue (Zhang et al. 2004, Kidd et al. 2007c). Also, in a small series only 2 out of 5 SI-NETs were positive for TGF $\beta R 1$ and TGF $\beta$ R2 in the tumour stroma, suggesting lacking expression in fibroblasts (Wimmel et al. 2003). As TGFßR2 deletion in fibroblasts seems to increase the oncogenic potential of selected epithelial cells, this finding emphasizes the importance of investigating TGF $\beta$ signalling embedded in a concept of TME (Bhowmick et al. 2004).

In vitro, it was shown that BON1 cell conditioned medium could induce TGF $\beta$-mediated proliferation of AKR-2B cells, a mouse fibroblast cell line, suggesting that factors produced by NET cells influence fibroblast function. Furthermore, it was confirmed that TGF $\beta$ stimulation results in an increased production of TGF $\beta$ by these fibroblasts, confirming a positive autocrine feedback loop (Beauchamp et al. 1991). Moreover, CAFs isolated from a patient with a fibrotic SI-NET show increased transcription of CTGF after TGF $\beta 1$ stimulation (Kidd et al. 2007c). However, the effect of TGF $\beta$ differs on the model used. TGF $\beta 1$ has an inhibitory effect on growth of normal EC and BON1 cells, while it has a proliferative effect on KRJ-I cells (Wimmel et al. 2003, Kidd et al. $2007 b$ ). Exposure of KRJ-I cells to TGF $\beta 1$ resulted in phosphorylation of SMAD2, indicating an intact TGF $\beta$ R2 signalling, even though KRJ-I cells have decreased TGF $\beta$ R2 expression compared to normal EC cells. However, there was a decreased nuclear staining of phosphorylated SMAD2 in these cells, which is suggestive of a block at the level of SMAD nuclear translocation (Kidd et al. 2007b).
Furthermore, in a series of 48 SI-NETs, 22 had mutations or deletions in genes (Banck et al. 2013). This underlines the importance of the TGF $\beta$ signalling pathway in SI-NETs. Tumours with inactivating mutations in TGF $\beta$ signalling pathway can paradoxically benefit from a TGF $\beta$-rich microenvironment by the effects of intact signalling in the tumour stroma. These favour tumour progression, e.g. production of growth factors and stimulation of invasion and metastasis, while the suppressive effects of TGF $\beta$ signalling on tumour cells are avoided by inactivating mutations (Massague 2012).

\section{Platelet-derived growth factor (PDGF)}

PDGF is released in response to tissue injury, and it is shown to be involved in multiple fibrotic diseases such as scleroderma, intestinal fibrosis in Crohn's disease and renal fibrosis (Bonner 2004). PDGF has a strong proliferative effect on fibroblasts and can induce proliferation of epithelial cancer cells (Rybinski et al. 2014). The profibrotic effects of PDGF are mediated by binding to the PDGF $\alpha$ - and $\beta$-receptors (PDGFR $\alpha$ and PDGFR $\beta$ ). Expression of the receptors differs between cell types and can be induced by diverse factors, such as TGF $\beta$. Furthermore, upregulation of both receptors is found in many fibrotic diseases, although it depends on the involved tissue which of the PDGF receptors is predominantly upregulated (Bonner 2004).

In stromal cells of SI-NETs, the PDGFR $\beta$ was detected by IHC in $66-85 \%$. The IHC staining was mostly found adjacent to tumours cells, without staining of the tumours cells themselves. The positive cells showed frequently a fibroblastic morphology with muscle actin antigen positivity, suggesting an activated phenotype characteristic of CAFs (Funa et al. 1990, Chaudhry et al. 1992, Kalluri 2016). Furthermore, PDGFR $\beta$ immunoreactivity was more prevalent in metastases and associated with the presence of macrophages. There was no correlation with urinary 5-HIAA excretion (Funa et al. 1990). On the other hand, the majority of tumour cells are positive for PDGFR $\alpha$ and PDGF with limited focal staining in the stroma surrounding positive tumour cells (Chaudhry et al. 1993). These results suggest that components of the TME (e.g. tumour cells, macrophages) induce PDGFR $\beta$ expression on adjacent fibroblasts and upregulate PDGFR $\beta$ activity in a paracrine fashion. Moreover, the increased expression of PDGFR $\beta$ in the stromal cells of metastases links it to tumour proliferation and metastatic potential. Together with the finding that $20 \%$ of SI-NET show copy number gains of $P D G F R$, suggesting augmented activation of this 
pathway in a subset of these tumours, inhibition of PDGF signalling is potentially an attractive therapeutic target (Banck et al. 2013).

\section{Basic fibroblast growth factor (FGF2)}

FGF2 is an important regulator of wound healing and is known to have a strong mitogenic effect on fibroblasts. It can be induced by TGF $\beta$ and is linked to several fibrotic disorders (Rybinski et al. 2014). Its role in cancer is less obvious. FGF2 is suggested to have anti-apoptotic, proliferative effects on tumour cells and to stimulate angiogenesis. Conversely, other studies have shown that in some conditions, FGF2 has a tumour-suppressive role, making it a complex signalling factor to investigate (Turner \& Grose 2010).

Studies performed on SI-NETs showed positive IHC staining for FGF2 in $60-100 \%$ of tumour cells and adjacent stroma (Chaudhry et al. 1993, Zhang et al. 2004). Neither the prevalence nor the intensity of FGF2 staining was correlated to MF (Zhang et al. 2004). In vitro, FGF2 is shown to be expressed by BON1 cells and to stimulate proliferation of these cells (Beauchamp et al. 1991). FGF receptors are found in most SI-NETs, both in tumour and stromal cells (Facco et al. 1998, Wulbrand et al. 1998). Although the presence of FGF2 in tumour cells and stroma suggests involvement in cellular processes of the TME, the effect of FGF2 on tumour development remains uncertain. Therefore, FGF2-targeted therapy remains to be considered with caution, until the effects of FGF2 signalling are better understood (Akl et al. 2016).

\section{Transforming growth factor alpha (TGF $\alpha$ ) and epidermal growth factor receptor (EGFR)}

TGF $\alpha$ and epidermal growth factor (EGF) are both ligands of EGFR, a receptor tyrosine kinase (Jorissen et al. 2003). After binding of the ligand, the EGFR activates multiple signalling pathways via its tyrosine kinase activity (Jorissen et al. 2003). Like FGF2, EGFR signalling is involved in wound healing, stimulates proliferation of mesenchymal cells and correlates with fibrotic and malignant diseases (Rybinski et al. 2014).

The expression of EGFR detected in SI-NETs differs vastly between studies, ranging from 33 to 100\% (Nilsson et al. 1995, Krishnamurthy \& Dayal 1997, Wulbrand et al. 1998, Shah et al. 2006). In 2006, Shah and colleagues analysed 98 NETs, of which 42 were from midgut origin, for the presence of EGFR. In $96 \%$ of the samples, there was positive IHC staining for EGFR, predominantly cytoplasmic in tumour cells and absent in the surrounding stroma (Shah et al. 2006).

Of all EGFR ligands, TGF $\alpha$ is most extensively investigated in SI-NETs. It was found to be present in all specimens in a series of 20 SI-NET metastases as well as in BON1 cells (Beauchamp et al. 1991, Nilsson et al. 1995). The expression of TGF $\alpha$ is co-localized with EGFR on cell membranes and cytoplasm of tumour cells, suggesting effective ligand binding and intracellular signalling (Nilsson et al. 1993). Also, TGFo is secreted by primary SI-NET cultures, which is not inhibited by targeting of the somatostatin receptor 2 (SSTR2) by octreotide, a somatostatin analogue (Nilsson et al. 1995). Furthermore, TGF $\alpha$ stimulates proliferation in SI-NET primary cell cultures and cell lines (e.g. BON1 and KRJ-I) (Nilsson et al. 1995, Siddique et al. 2009). This effect can be inhibited by blocking the EGFR, suggesting an autocrine regulatory loop (Nilsson et al. 1995). However, these studies focused mostly on the proliferative effect on tumour cells, leaving the role of EGFR signalling in SI-NET-associated fibrosis elusive. Therefore, possible effectiveness of targeting EGFR signalling by tyrosine kinase inhibitors for the treatment of MF remains uncertain (Bergsland et al. 2012).

\section{Connective tissue growth factor (CTGF, also known as (CN2)}

CTGF is a member of the CCN family of growth factors, which are induced by cytokines such as TGF $\beta$ and importantly also by serotonin (Leask \& Abraham 2006, Jacobson \& Cunningham 2012). Although CTGF can influence cell processes independently, it acts mainly by modifying signalling of other molecules. CTGF is involved in tissue repair and pathologic tissue fibrosis. CTGF enhances profibrotic actions of TGF $\beta$, EGF and FGF by increasing collagen synthesis, fibroblast proliferation and differentiation into myofibroblasts. As CTGF enhances the effect of tumourgenic and profibrotic growth factors, it is a potential target for therapy (Leask \& Abraham 2006, Adler et al. 2010). Treatment with CTGF-neutralizing antibodies has already been shown to decrease tumour growth and metastasis in pancreatic cancer models (Leask \& Abraham 2006).

SI-NETs have a high expression of CTGF compared to other neuroendocrine tumours (Kidd et al. 2007c, Cunningham et al. 2010). Immunoreactivity was strongest in SI-NET cells adjacent to fibrovascular stroma, suggesting a local effect on the tumour stroma interaction at the invasion border. Furthermore, CTGF co-localized with serotonin in $93 \%$ of tumour cells and with TGF $\beta$ 
in $80 \%$. The tumour stroma, however, shows little CTGF immunoreactivity (Cunningham et al. 2010). High expression of CTGF in tumour tissue of NETs was found to be correlated with SI-NETs, MF and serum levels of CTGF (Kidd et al. 2007c). However to date, no association has been found in SI-NETs between serum levels of CTGF and the presence of MF.

\section{Other growth factors}

Next to the previously discussed factors, many more mediators have been found to be present in SI-NETs. However, their effects on fibrosis and MF are much less well studied. In the next section, putative profibrotic molecules will be discussed. However, further research is needed to determine their importance in the deregulation of the TME and development of MF.

Nerve growth factor (NGF) was originally characterized by its effect on the development of peripheral sensory and sympathetic neurons. However, NGF signalling has protumourigenic, angiogenic and profibrotic effects also and is known to induce TGF $\beta$ expression (Vizza et al. 2015, Boilly et al. 2017). In SI-NETs, NGF expression is present on tumours cells and decreased in patients with mesenteric angiopathy and extensive fibrosis as compared to patients with limited MF (Nilsson et al. 1993, Zhang et al. 2004).

Substance P (SP) is a member of the tachykinin family and regulates biological functions mainly by binding to neurokinin-1 receptor (NK1R). SP is expressed by SI-NETs and is one of the kinins potentially involved in flushing and carcinoid heart disease (Vinik et al. 1990, Facco et al. 1998, Niederle et al. 2016). Furthermore, SP acts as a profibrotic cytokine in inflammatory fibrotic diseases such as intestinal and liver fibrosis and NK1R antagonist have been found to counteract the SP-induced fibrosis and secretion of profibrotic growth factors such as TGF $\beta$ (Koon et al. 2010, Wan et al. 2017). Also, SP has a proliferative and promigratory effect in cancer (Esteban et al. 2006). NK1R antagonists are already in clinical use as antiemetic drugs and the recent research done in SP/NKR1 pathway in fibrosis and mitogenesis generated new interest in NK1R antagonist as an antitumour and antifibrotic treatment option (Esteban et al. 2006, Wan et al. 2017). However, the contribution of the SP/NKR1 pathway to development MF is unknown, and further research is essential before use of NK1R antagonist as antiproliferative and antifibrotic therapy can be considered.

The insulin-like growth factor (IGF) system is an important regulator of cell proliferation and ageing processes. The most important molecules in this signalling network are the ligands IGF1 and IGF2, the receptors IGF1R and IGF2R and the IGF-binding proteins (IGFBPs). Increased IGF signalling by increased levels of ligands or receptors is associated with increased risk of cancer. IGFBPs modulate the bioavailability of IGFs and their role in cancer development is complex and bimodal (Pollak et al. 2004). The majority of SI-NETs expresses IGF1, IGFR1 and IGFBPs (Nilsson et al. 1993, Wulbrand et al. 2000). Media from primary SI-NETs cultures also contained IGF1 and incubation with IGF1 induced proliferation in BON1 cells and IGFR1-positive primary cultures (Nilsson et al. 1993, von Wichert et al. 2000). Conversely, only 1 out of 9 SI-NET specimens had expression of IGF2 or IGF2R (Wulbrand et al. 2000). As regulation of IGF signalling is complex and its function during SI-NET-associated fibrogenesis is unknown, further studies are needed to determine the role of the IGF system in MF (Pollak et al. 2004, Feghali-Bostwick 2005, Nishizawa et al. 2016).

\section{Developmental signalling pathways}

Embryonic development is tightly regulated by a limited number of signalling pathways. In adulthood, these pathways regulate tissue homeostasis and are known to be deregulated in aberrant wound healing, chronic fibrosis and cancer (Rybinski et al. 2014). The research performed in SI-NETs on three well-known pathways (Hedgehog, Notch and Wnt), which are all implicated both in fibrotic diseases and cancer, will be discussed below (Hoeft \& Kramann 2017).

Sonic Hedgehog (SHh) is the most studied Hedgehog ligand. Binding of SHh to Patched, its receptor, promotes expression of Gli transcription factors (Rybinski et al. 2014). Gli1 is the most abundant transcription factor and is shown to induce the expression of Snail. Subsequently, upregulation of Snail results in loss of E-cadherin and induction of epithelial-mesenchymal transition (EMT) (Rybinski et al. 2014). In models of lung, kidney, heart and liver fibrosis, SHh is upregulated after tissue injury. Also, SHh stimulation induced matrix production and myofibroblastic differentiation in vitro (Hoeft \& Kramann 2017). In a series of 37 SI-NETs, the Hedgehog signalling pathway was assessed by IHC. SHh expression was found in $73 \%$ of tumours and 59\% stained positive for Snail. Snail-positive cells were mostly identified at the invasive front of the tumours and had suppressed E-cadherin expression (Fendrich et al. 2007). Also, it was found that Snail1 expression is associated with worse prognosis and metastatic spread in NETs (Galvan et al. 2013). However, 
the role of Hedgehog signalling in the development of MF is still undetermined.

Aberrant Notch signalling is found in cancer and fibrosis (Hoeft \& Kramann 2017, Nowell \& Radtke 2017). Increased Notch signalling has a profibrotic effect, as is demonstrated in renal and hepatic fibrosis (Hoeft \& Kramann 2017). On the other hand, Notch signalling in cancer is more complex with pro- and antitumourigenic effects depending on the context (Nowell \& Radtke 2017). Notch canonical signalling is induced by ligand binding to one of the four Notch receptors. This ligand binding promotes the expression of target genes of which hairy/ enhancer of split (HES) and hairy/enhancer of split related with YRPW motif (HEY) are best characterized. Also, canonical Notch signalling represses expression of transcriptional factor achaete-scute complex-like 1 (ASCL1) (Nowell \& Radtke 2017). The role of ASCL1 in tumourigenesis is complex and not well studied, but in transfected BON1 cells, Notch signalling mediated loss of ASCL1 and decreased serotonin production (Kunnimalaiyaan et al. 2005, Nakakura et al. 2005). However, the findings on Notch signalling in SI-NETs in vivo are conflicting. In 2005, Nakakura and colleagues demonstrated the transcription of NOTCH1, NOTCH2, NOTCH3, HES1, HEY1 and HEY2 in a series of 8 SI-NETs to be comparable to normal tissue, but upregulated ASCL1 transcription was found in 50\% of the tumours (Nakakura et al. 2005). However, later research showed no NOTCH1 and HES1 IHC positivity on a tissue micro-array of 31 SI-NETs, underscoring the need for further research to unravel the role of this signalling pathway in SI-NETs (Wang et al. 2013).

The canonical Wnt/ $\beta$-catenin signalling controls gene expression by regulating the amount of $\beta$-catenin. In the absence of a Wnt signal, $\beta$-catenin cytoplasmic levels are maintained low by binding to a destruction complex consisting of multiple proteins (Hoeft \& Kramann 2017). One of these proteins is the adenomatous polyposis coli protein (APC), which associated with familial adenomatous polyposis and sporadic colon cancer (Bottarelli et al. 2013, Hoeft \& Kramann 2017). In the presence of a Wnt signal, $\beta$-catenin dissociates and the destruction complex is inactivated. This results in an accumulation of $\beta$-catenin that consequently can translocate to the nucleus where it activates target gene expression. Although mutations in the APC gene have been found in $23 \%$ of SI-NET cases, only membranous expression of $\beta$-catenin has been found in SI-NETs (Fendrich et al. 2007, Bottarelli et al. 2013). Furthermore, the severity of MF was not correlated with $\beta$-catenin expression (Zhang et al. 2004). These findings suggest a minor role for $\mathrm{Wnt} / \beta$-catenin signalling in SI-NET development and fibrosis.

\section{Learning from other diseases}

In the previous part, we have discussed a variety of known and putative mediators of fibrosis in SI-NETs. However, research done both in malignant and benign diseases with profound fibrosis suggest an even wider array of factors that influence tissue homeostasis and when deregulated can induce fibrosis. Since the microenvironment in wound healing shares many commonalities with the stroma in chronic fibrosis, the role of inflammation and the adaptive immune response seems important also for the development of fibrosis. Secretion of specific profibrotic cytokines and chemokines within the tissue microenvironment is found to be largely homologous in different fibrotic diseases. Next to immune system, tissue hypoxia and activation of the renin-angiotensin system (RAS) are also shown to be present in many fibrotic diseases such as cardiac and hepatic fibrosis (Wynn 2008). Angiotensin II is able to induce fibrosis via the AT1 receptor and increased expression of profibrotic growth factors such as TGF $\beta$, FGF2 and PDGF (Ager et al. 2008, Murphy et al. 2015). Furthermore, overexpression of AT1 receptor is found in many malignancies, linking RAS to tumour and fibrosis development (Ager et al. 2008). Finally, recent insights into microRNAs show an even more intricate network of regulatory mechanisms of fibrogenesis, especially since numerous common microRNA alternations are found over a wide array of different fibrotic diseases, such as renal, hepatic and pulmonary fibrosis (Vettori et al. 2012). As there is a paucity of research on the precise role of these mediators in SI-NET-associated fibrosis, we have not elaborated on these subjects. However, focusing future research on these mediators could illuminate new therapeutic targets.

\section{Treatment of mesenteric fibrosis}

MF can cause severe abdominal complications such as intestinal obstruction, oedema or ischaemia (Makridis et al. 1990). To date, treatment of MF is limited to symptomatic relief by bowel resection or bypass (Makridis et al. 1990, Modlin et al. 2004). However, abdominal surgery in patients with MF is challenging and can lead to complications such as short-bowel syndrome and bile-salt diarrhoea (Makridis et al. 1990). Furthermore, resection is not always possible due to the patient's clinical condition or disease characteristics such as the location of the mesenteric mass and encasement of the superior 
mesenteric vein (SMV) or superior mesenteric artery (SMA). Consequently, vascular stenosis and the following ischaemia or bowel wall oedema is an important cause of abdominal complaints in patients with MF. Therefore, stenting of the SMV in case of stenosis and encasement has been suggested for symptom relief. In a small series of seven patients with SI-NET and proven SMV obstruction, stenting resulted in four patients in improvement of their symptoms (Hellman et al. 2010). However, these results have not been replicated in larger studies, and in our experience, SMV stenting is a complex procedure with often disappointing results. However, in the era of targeted therapy and with increasing knowledge of the pathobiological processes, possible new avenues for treating and preventing MF can be developed. In the next section, we discuss possible antifibrotic agents by linking the known mediators of fibrosis in SI-NETs with drugs currently used to target these mediators, both in SI-NETs and other diseases (Table 1).

\section{Somatostatin analogues (SSAs)}

SSAs are first-line therapy with proven efficacy on tumour growth control in SI-NETs (Pavel et al. 2016). Two commercially available agents, octreotide and lanreotide, also effectively reduce carcinoid syndrome symptoms (Modlin et al. 2010, Pavel et al. 2016). Moreover, SSAs are known to attenuate fibrosis in animal models of peritoneal sclerosis, pulmonary and liver fibrosis by among others reducing the secretion of profibrotic growth factors such as TGF (Lang et al. 2005, Borie et al. 2008, Ertilav et al. 2011) However, the effect of SSAs on MF in SI-NETs has not been examined. Also, while approximately half of the patients have a reduction of bioactive peptide secretion of $>50 \%$, complete biochemical response in carcinoid syndrome occurs only in a minority of patients (Modlin et al. 2010). Since increased urinary 5-HIAA excretion is associated with MF, effective inhibition of serotonin production could reduce the risk of development and growth of MF in patients with SI-NET. It can therefore be hypothesized that SSA therapy should aim to fully normalize serotonin production in order to minimize development of fibrosis, although this should be evaluated in prospective studies.

\section{Serotonin synthesis inhibitors}

Serotonin is synthesized in two enzymatic steps from the essential amino acid tryptophan. First, tryptophan is hydroxylated by tryptophan hydroxylase (THP) to 5-hydrotryptophan (5-HTP) and in a second step, 5-HTP is decarboxylated to form serotonin (MohammadZadeh et al. 2008). Almost sixty years ago, the first attempts to block peripheral serotonin synthesis were undertaken. These first attempts aimed to inhibit 5-HTP decarboxylation by agents such as phenylacetic acid and $\alpha$-methyl-dopa. These drugs had a moderate effect on decreasing serotonin production and side effects that limited their clinical use (Sandler \& Close 1959, Sjoerdsma et al. 1960).

The next step was to inhibit THP. Using parachlorophenylalanine (PCPA), serotonin production and carcinoid syndrome symptoms could be reduced. However, the psychiatric side effects precluded therapeutic use of the compound (Engelman et al. 1967). The search for THP inhibitors that primarily inhibit peripheral serotonin synthesis resulted in the development of telotristat. This year, a phase III study was published comparing the effect of telotristat with placebo on carcinoid syndrome symptoms. Compared to placebo, the majority of patient had $>30 \%$ reduction of 5-HIAA excretion (Kulke et al. 2017). However, also this study did not aim to completely normalize serotonin production nor was the effect on fibrosis assessed.

\section{5-HT receptor antagonist}

Next to inhibition of serotonin synthesis, targeting 5 -HT receptors can modify serotonin signalling. As the profibrotic effects of serotonin seem to be mainly mediated via the $5-\mathrm{HT}_{1 \mathrm{~A} / \mathrm{B}}$ and $5-\mathrm{HT}_{2 \mathrm{~A} / \mathrm{B}}$ receptors, drugs targeting these receptors should be considered for antifibrotic treatment (Svejda et al. 2010, Mann \& Oakley 2013). Non-selective $5-\mathrm{HT}_{2}$ receptor antagonists such as cyproheptadine and ketanserin were found to be able to reduce diarrhoea in the context of carcinoid syndrome (Robertson 1990, Moertel et al. 1991). However, due to the modest effects compared to SSAs and serious adverse effect of ketanserin, the clinical utility of these drugs is limited (Robertson 1990, Moertel et al. 1991).

However, advancements have been made with new potential antifibrotic agents. Terguride, a $5-\mathrm{HT}_{2 \mathrm{~A} / \mathrm{B}}$ receptor antagonist, is proven to reduce the profibrotic effects of serotonin in animals (Hauso et al. 2007). Furthermore, in a phase II study in scleroderma patients it was well tolerated and resulted in amelioration of the skin fibrosis (Distler et al. 2016). Even though more research is needed to establish the effect of terguride on SI-NET-associated fibrosis, it sparks hope for a potent, well-tolerated antifibrotic therapy. 
Table 1 Summary of known profibrotic growth factors secreted by small intestinal neuroendocrine tumours (SI-NETs) and studies on therapeutic targeting of these growth factors in SI-NETs and fibrotic diseases.

\begin{tabular}{|c|c|c|}
\hline $\begin{array}{l}\text { Growth } \\
\text { factor } \\
\text { secreted by } \\
\text { SI-NETs } \\
\end{array}$ & Receptors on SI-NETs & Effect in SI-NETs \\
\hline Serotonin & $\begin{array}{l}\text { 5-HT2b receptor } \\
\text { No information on } \\
\text { expression of other } \\
\text { 5-HT receptor subtypes }\end{array}$ & $\begin{array}{l}\text { Proliferation } \\
\text { Growth factor secretion: } \\
\text { TGF } \beta 1, \text { CTGF, FGF2 and } \\
\text { serotonin }\end{array}$ \\
\hline TGF $\beta$ & $\begin{array}{l}\text { TGF } \beta \text { R1 } \\
\text { TGF } \beta \text { R2 }\end{array}$ & $\begin{array}{l}\text { Proliferation of KRJ-I } \\
\text { cells and CAFs } \\
\text { Growth factor secretion } \\
\text { by fibroblasts: CTGF, } \\
\text { TGF } \beta\end{array}$ \\
\hline PDGF & $\begin{array}{l}\text { PDGFR } \alpha \text { (tumour cells) } \\
\text { PDGFR } \beta \text { (stromal cells in } \\
\text { TME) }\end{array}$ & $\begin{array}{l}\text { No functional studies in } \\
\text { SI-NETs }\end{array}$ \\
\hline FGF2 & FGF receptor & $\begin{array}{l}\text { Proliferation of BON1 } \\
\text { cells }\end{array}$ \\
\hline TGF $\alpha$ & EGFR & $\begin{array}{l}\text { Proliferation of BON1 } \\
\text { and KRJ-I cells }\end{array}$ \\
\hline CTGF & $\begin{array}{l}\text { No high affinity } \\
\text { CTGF-specific receptor } \\
\text { known }\end{array}$ & $\begin{array}{l}\text { High CTGF expression } \\
\text { correlated to SI-NETs } \\
\text { and MF }\end{array}$ \\
\hline
\end{tabular}

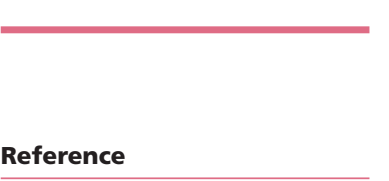

Svejda et al. (2010) SSAs

Potential targeted therapy

Potential targeted therapy
SSAs

Telotristat (THP inhibitor)

Terguride $\left(5-\mathrm{HT}_{2 \mathrm{~A} / \mathrm{B}}\right.$ receptor antagonist)

Beauchamp et al. (1991), No successful direct inhibition to Chaudhry et al. (1994),

date

Wimmel et al. (2003),

Kidd et al. $(2007 b, c)$

Interference TGF $\beta$ signalling by:

SSAs

Enalapril (ACE-inhibitor)

Tamoxifen

Imatinib

Chaudhry et al. (1992),

Chaudhry et al. (1993)

Beauchamp et al. (1991),

Chaudhry et al. (1993),

Facco et al. (1998),

Wulbrand et al. (1998),

Zhang et al. (2004)

Beauchamp et al. (1991),

Nilsson et al. (1995),

Krishnamurthy and Dayal

(1997), Wulbrand et al.

(1998), Shah et al. (2006) Gefitinib

Leask and Abraham (2006), Anti-CTGF antibody

Kidd et al. (2007c).

Cunningham et al. (2010)

\section{Tyrosine kinase inhibitors (TKIs)}

Tyrosine kinases consist of a large family of enzymes that are important mediators of cellular signal transduction. Receptor tyrosine kinases are activated by diverse extracellular signal molecules such as EGF, TGF $\alpha$, PDGF and FGF (Rybinski et al. 2014). Furthermore, the TGF $\beta$ signalling pathway is also influenced by downstream effects of receptor tyrosine kinase signalling (Massague 2012). As tyrosine kinase signalling pathways are involved in both cancer and fibrosis development, they are an interesting therapeutic target in SI-NETs (Rybinski et al. 2014).

Unfortunately, the efficacy of TKIs in SI-NETs on tumour grow'th suppression seems limited and accompanied by significant toxicity (Hobday et al. 2007, Kulke et al. 2008, Phan et al. 2010, Chan et al. 2013). Furthermore, the studies examining the effect of TKIs in SI-NETs focused neither on reduction of fibrosis nor 


\section{Studies}

First line of treatment for

functional or progressive SI-NET

Phase III study on carcinoid syndrome symptoms

No study in fibrotic diseases

Phase II scleroderma patients

No study in SI-NETS

First line of treatment for

functional or progressive SI-NET

Preclinical studies on fibrogenesis

Preclinical study

Case studies and series in patients with metastasized SI-NET

Case series in patients with sclerodermatous graft-vs-host disease and systemic sclerosis No study in SI-NETS

Preclinical studies on cancer proliferation in SI-NETs

Preclinical studies fibrogenesis in pulmonary and liver fibrosis

Phase II study in combination with everolimus

Preclinical studies on fibrogenesis in liver and pulmonary fibrosis

Preclinical studies on SI-NETs

Preclinical studies on fibrogenesis in pulmonary fibrosis

Phase I study in patients with diabetes and microalbumineria No study in SI-NETS
Effect in SI-NETs

Half of patients have reduction of bioactive peptide secretion of $>50 \%$

Reduction of stool movements

N/A

Reduction of peritoneal sclerosis, pulmonary and liver fibrosis in animal models

Reduction of BON1 cell proliferation

Inconsistent reduction of tumour volume and carcinoid syndrome symptoms.

N/A

complaints and myelosuppresion

Sirolimus; reduction of KRJ-I Infections, GI complaints and cell proliferation myelosuppresion ACE-inhibitors well tolerated No toxicity reported

Adverse effect

Reference

Gl complaints, cholelithiasis

Nausea, asymptomatic increased gamma-glutamyl transferase

Nausea

GI complaints, cholelithiasis

Distler et al. (2016)

Lang et al. (2005), Borie et al. (2008), Ertilav et al. (2011)

Fendrich et al. (2014)

Stathopoulos et al. (1981), Myers et al. (1982), Moertel et al. (1984),

Arganini et al. (1989)

Distler and Distler (2010)

Kidd et al. (2007a), Akl et al. (2016), Pavel et al. (2016)

Enrollment SI-NET stopped Increased toxicity compared to due to insufficient efficacy everolimus monotherapy

Bergsland et al. (2012)

Reduction of KRJ-I cell proliferation

N/A

Stomatitis, Gl-disorders

Kidd et al. (2007a)

Well tolerated

Adler et al. (2010)

5-HT, serotonin; ACE, angiotensin-converting enzyme; CAFs, cancer-associated fibroblasts; CTGF, connective tissue growth factor; EGFR, epidermal growth factor receptor; FGF, fibroblast growth factor; FGF2, basic fibroblast growth factor; GI, gastrointestinal; MF, mesenteric fibrosis; PDGF, platelet-derived growth factor; PDGFR, platelet-derived growth factor receptor; SI-NET, small intestinal neuroendocrine tumour; SSAs, somatostatin analogues; $\mathrm{TGF} \alpha$, transforming growth factor alpha; TGF $\beta$, transforming growth factor beta; TGF $\beta$, transforming growth factor beta receptor; THP, tryptophan hydroxylase.

fibrotic complications (Hobday et al. 2007, Kulke et al. 2008, Phan et al. 2010, Chan et al. 2013).

While the focus in SI-NETs has been on inhibition of vascular endothelial growth factor (VEGF) signalling by TKIs and tumour growth, research on fibrotic diseases such as scleroderma focuses on TKIs targeting c-alb kinases and PDGF receptors. By blocking these kinases, important downstream signalling molecules such as TGF $\beta$ are reduced (Distler \& Distler 2010). As these signalling molecules are also involved in tumourigenic processes,
TKIs such as imatinib, which targets c-abl kinases and PDGFRs, could result in antitumourigenic changes in the TME (Pietras \& Hanahan 2005). Furthermore, clinical studies with imatinib show decreased organ fibrosis in patients with scleroderma and pulmonary fibrosis (Distler \& Distler 2010). Since the signalling pathways involved in the development of fibrosis in SI-NETs are similar to those fibrotic diseases, the use of TKIs should be extended beyond tumour growth control and also be evaluated as antifibrotic therapy. 


\section{Other antifibrotic agents}

As fibrotic diseases share many commonalities with cellular processes in SI-NETs, potential effective antifibrotic agents can be identified by assessing drugs used in fibrotic diseases such as retroperitoneal fibrosis, idiopathic pulmonary fibrosis and scleroderma, but also more common disorders such as cardiac and renal fibrosis (Rybinski et al. 2014). Often fibrosis occurs after tissue injury, and hypertension is a frequent cause of heart and kidney injury. As RAS is an important regulator of cardiovascular homeostasis, inhibition of RAS by angiotensin-converting enzyme (ACE) inhibitors and angiotensin II receptor blockers (ARBs) forms one of the cornerstones of hypertension treatment (Murphy et al. 2015). However, the functions of RAS signalling extend beyond cardiovascular homeostasis. As discussed earlier, RAS activation is also involved in tumour and fibrosis development (Ager et al. 2008, Murphy et al. 2015). Epidemiological studies provide evidence that RAS inhibition may reduce tumour development and progression (Ager et al. 2008). In addition, in vitro ACE inhibition is shown to reduce BON1 cell proliferation (Fendrich et al. 2014). Since ACE inhibitors and ARBs are commonly used as antihypertensive treatment with few side effects, they might be considered as coadjuvant therapy in SI-NET treatment, but further studies are needed to confirm their clinical efficacy in this setting.

Another antifibrotic agent used in fibrotic diseases such as desmoid tumours and retroperitoneal fibrosis is tamoxifen (van Bommel et al. 2006). Tamoxifen is a synthetic nonsteroidal selective oestrogen receptor modulator (SERM), developed for the treatment of breast cancer. The antifibrotic effect seems to be mediated by an inhibitory effect of tamoxifen on TGF $\beta$ secretion by fibroblasts (Mikulec et al. 2001). Moreover, tamoxifen has been used in SI-NETs for tumour growth control and amelioration of carcinoid syndrome symptoms with varying success (Stathopoulos et al. 1981, Myers et al. 1982, Moertel et al. 1984, Arganini et al. 1989). However, better patient selection and focus on the antifibrotic effects might establish tamoxifen as a treatment option for fibrotic complications of SI-NETs.

\section{Conclusion}

Since the development of a variety of palliative treatments, the survival of patients with metastasized SI-NETs has improved. As a result, morbidity caused by MF and the lack of therapeutic options have become major issues. In order to elucidate potential new roads for scientific research and therapies to improve the management of $\mathrm{MF}$, we first discussed the pathobiology of MF. A deregulation of the cellular processes in the TME is at the core of fibrosis development. However, research on fibrosis in SI-NETs has just started to focus on the TME and should be extended beyond the interaction between tumour cells and fibroblasts. Especially knowledge about the changes in the composition and biomechanical properties of the ECM during tumourigenesis and fibrosis development in SI-NETs is lacking. In order to gain more insight in cellular processes in the TME, in vitro research should shift from 2D monocultures to more intricate systems such as cocultures and 3D cultures and the possibility of in vivo models should be explored. Also, the use of the BON1 cell line as an in vitro model for SI-NETs is not optimal as it is of pancreatic origin and known to differ substantially in gene level transcripts from EC cell-derived NET cell lines (Grozinsky-Glasberg et al. 2012). Since tumour cells and other components of the TME communicate via a multitude of hormones, growth factors and signalling pathways, we have discussed the putative profibrotic factors in SI-NETs. However, the exact effects and modulation of many of the discussed signalling molecules remain incompletely mapped. Therefore, targeted inhibition of these pathways should first be investigated in experimental models. Also, insights gained in other fibrotic diseases point to an even more intricate network of regulators of tissue homeostasis and fibrosis development with factors such as cytokines, microRNAs and hypoxia and RAS signalling. To date, therapeutic options are mainly limited to surgery. However, due to patient or disease characteristics, not all patients can undergo surgery, and intestinal resection can lead to complications with significant morbidity. Therefore, we discussed possible alternatives for patients with SI-NETs suffering from the complications of MF. However, in order to be able to determine the efficacy of these treatments, it is important to gain insight into the natural development of MF and design clinical trials focused on assessing drug effects on MF.

\section{Supplementary data}

This is linked to the online version of the paper at https://doi.org/10.1530/ ERC-17-0380.

\section{Declaration of interest}

A Blažević, L J Hofland: no disclosures to report. R A Feelders has received research grants from Ipsen and Novartis. J Hofland has received speaker and travel fees from Ipsen and Novartis. W W de Herder has joined advisory boards for Ipsen and Novartis.
2018 Society for Endocrinology Published by Bioscientifica Ltd. Printed in Great Britain 


\section{Funding}

Study was funded by an unrestricted fund of IPSEN.

\section{Acknowledgements}

The authors would like to thank Wichor Bramer for his assistance with systematic literature retrieval.

\section{References}

Adler SG, Schwartz S, Williams ME, Arauz-Pacheco C, Bolton WK, Lee T, Li D, Neff TB, Urquilla PR \& Sewell KL 2010 Phase 1 study of antiCTGF monoclonal antibody in patients with diabetes and microalbuminuria. Clinical Journal of the American Society of Nephrology 5 1420-1428. (https://doi.org/10.2215/CJN.09321209)

Ager EI, Neo J \& Christophi C 2008 The renin-angiotensin system and malignancy. Carcinogenesis 29 1675-1684. (https://doi.org/10.1093/ carcin/bgn171)

Akl MR, Nagpal P, Ayoub NM, Tai B, Prabhu SA, Capac CM, Gliksman M, Goy A \& Suh KS 2016 Molecular and clinical significance of fibroblast growth factor 2 (FGF2 /bFGF) in malignancies of solid and hematological cancers for personalized therapies. Oncotarget 7 44735-44762. (https://doi.org/10.18632/ oncotarget.8203)

Arganini M, Spinelli C, Cecchini GM \& Miccoli P 1989 Long term treatment with tamoxifen for metastatic carcinoid tumor. Acta Chirurgica Belgica 89 209-211.

Banck MS, Kanwar R, Kulkarni AA, Boora GK, Metge F, Kipp BR, Zhang L, Thorland EC, Minn KT, Tentu R, et al. 2013 The genomic landscape of small intestine neuroendocrine tumors. Journal of Clinical Investigation 123 2502-2508. (https://doi.org/10.1172/ JCI67963)

Beauchamp RD, Coffey RJ Jr, Lyons RM, Perkett EA, Townsend CM Jr \& Moses HL 1991 Human carcinoid cell production of paracrine growth factors that can stimulate fibroblast and endothelial cell growth. Cancer Research 51 5253-5260.

Bellono NW, Bayrer JR, Leitch DB, Castro J, Zhang C, O’Donnell TA Brierley SM, Ingraham HA \& Julius D 2017 Enterochromaffin cells are gut chemosensors that couple to sensory neural pathways. Cell 170 185.e116-198.e116. (https://doi.org/10.1016/j.cell.2017.05.034)

Bergsland E, K., Lindsey W, Andrew HK, Margaret AT, Wolfgang Michael K, Robin Katie K, Thomas W, Iche S, Jimmy H, Eric KN, et al. 2012 A phase II study to evaluate the safety and efficacy of RAD001 plus erlotinib in patients with well-differentiated neuroendocrine tumors (NET). Journal of Clinical Oncology 30 285-285. (https://doi.org/10.1200/jco.2012.30.4_suppl.285)

Bhowmick NA, Chytil A, Plieth D, Gorska AE, Dumont N, Shappell S, Washington MK, Neilson EG \& Moses HL 2004 TGF-beta signaling in fibroblasts modulates the oncogenic potential of adjacent epithelia. Science 303 848-851. (https://doi.org/10.1126/ science.1090922)

Boilly B, Faulkner S, Jobling P \& Hondermarck H 2017 Nerve dependence: from regeneration to cancer. Cancer Cell 31 342-354. (https://doi.org/10.1016/j.ccell.2017.02.005)

Bonner JC 2004 Regulation of PDGF and its receptors in fibrotic diseases. Cytokine and Growth Factor Reviews 15 255-273. (https://doi. org/10.1016/j.cytogfr.2004.03.006)

Borie R, Fabre A, Prost F, Marchal-Somme J, Lebtahi R, MarchandAdam S, Aubier M, Soler P \& Crestani B 2008 Activation of somatostatin receptors attenuates pulmonary fibrosis. Thorax 63 251-258. (https://doi.org/10.1136/thx.2007.078006)

Bottarelli L, Azzoni C, Pizzi S, D’Adda T, Silini EM, Bordi C \& Rindi G 2013 Adenomatous polyposis coli gene involvement in ileal
C 2018 Society for Endocrinology Published by Bioscientifica Ltd. Printed in Great Britain enterochromaffin cell neuroendocrine neoplasms. Human Pathology 44 2736-2742. (https://doi.org/10.1016/j.humpath.2013.06.019)

Chan JA, Mayer RJ, Jackson N, Malinowski P, Regan E \& Kulke MH 2013 Phase I study of sorafenib in combination with everolimus (RAD001) in patients with advanced neuroendocrine tumors. Cancer Chemotherapy and Pharmacology 71 1241-1246. (https://doi. org/10.1007/s00280-013-2118-9)

Chaudhry A \& Oberg K 1993 Transforming growth-factor-alpha and epithelial growth-factor receptor expression in neuroendocrine tumors of the digestive-system. Diagnostic Oncology 3 81-85.

Chaudhry A, Papanicolaou V, Oberg K, Heldin CH \& Funa K 1992 Expression of platelet-derived growth factor and its receptors in neuroendocrine tumors of the digestive system. Cancer Research $\mathbf{5 2}$ 1006-1012.

Chaudhry A, Funa K \& Oberg K 1993 Expression of growth factor peptides and their receptors in neuroendocrine tumors of the digestive system. Acta Oncologica 32 107-114. (https://doi. org/10.3109/02841869309083898)

Chaudhry A, Oberg K, Gobl A, Heldin CH \& Funa K 1994 Expression of transforming growth factors $\beta 1, \beta 2, \beta 3$ in neuroendocrine tumors of the digestive system. Anticancer Research 14 2085-2091.

Cox TR \& Erler JT 2011 Remodeling and homeostasis of the extracellular matrix: implications for fibrotic diseases and cancer. Disease Models and Mechanisms 4 165-178. (https://doi.org/10.1242/ dmm.004077)

Cunningham JL, Tsolakis AV, Jacobson A \& Janson ET 2010 Connective tissue growth factor expression in endocrine tumors is associated with high stromal expression of $\alpha$-smooth muscle actin. European Journal of Endocrinology 163 691-697. (https://doi.org/10.1530/EJE10-0420)

de Herder WW 2005 Tumours of the midgut (jejunum, ileum and ascending colon, including carcinoid syndrome). Best Practice and Research: Clinical Gastroenterology 19 705-715. (https://doi. org/10.1016/j.bpg.2005.05.007)

Distler JH \& Distler O 2010 Tyrosine kinase inhibitors for the treatment of fibrotic diseases such as systemic sclerosis: towards molecular targeted therapies. Annals of the Rheumatic Diseases 69 (Supplement 1) i48-i51. (https://doi.org/10.1136/ard.2009.120196)

Distler O, Maurer B, Vettori S, Blumhardt S, Frey D, Distler A, Beyer C \& Distler JH 2016 OP0034 the serotonin receptor 2 inhibitor terguride has beneficial effects on skin fibrosis: results from a phase 2 proof of concept study. Annals of the Rheumatic Diseases 75 66-66. (https://doi.org/10.1136/annrheumdis-2016-210037)

Drozdov I, Kidd M, Gustafsson BI, Svejda B, Joseph R, Pfragner R \& Modlin IM 2009 Auto-regulatory effects of serotonin on proliferation and signaling pathways in lung and small intestine neuroendocrine tumor cell lines. Cancer 115 4934-4945. (https://doi.org/10.1002/ cncr.24533)

Druce MR, Bharwani N, Akker SA, Drake WM, Rockall A \& Grossman AB 2010 Intra-abdominal fibrosis in a recent cohort of patients with neuroendocrine ('carcinoid') tumours of the small bowel. Quarterly Journal of Medicine 103 177-185. (https://doi.org/10.1093/qjmed/ hcp191)

Engelman K, Lovenberg W \& Sjoerdsma A 1967 Inhibition of serotonin synthesis by para-chlorophenylalanine in patients with the carcinoid syndrome. New England Journal of Medicine 277 1103-1108. (https://doi.org/10.1056/NEJM196711232772101)

Ertilav M, Hur E, Bozkurt D, Sipahi S, Timur O, Sarsik B, Akcicek F \& Duman S 2011 Octreotide lessens peritoneal injury in experimental encapsulated peritoneal sclerosis model. Nephrology 16 552-557. (https://doi.org/10.1111/j.1440-1797.2011.01460.x)

Esteban F, Munoz M, Gonzalez-Moles MA \& Rosso M 2006 A role for substance $\mathrm{P}$ in cancer promotion and progression: a mechanism to counteract intracellular death signals following oncogene activation or DNA damage. Cancer and Metastasis Reviews 25 137-145. (https://doi.org/10.1007/s10555-006-8161-9) 
Facco C, La Rosa S, Dionigi A, Uccella S, Riva C \& Capella C 1998 High expression of growth factors and growth factor receptors in ovarian metastases from ileal carcinoids: An immunohistochemical study of 2 cases. Archives of Pathology and Laboratory Medicine 122 828-832.

Feghali-Bostwick CA 2005 IGF-I: mediator of fibrosis or carcinogenesis? American Journal of Physiology: Lung Cellular and Molecular Physiology 288 L803-L804. (https://doi.org/10.1152/ajplung.00012.2005)

Fendrich V, Waldmann J, Esni F, Ramaswamy A, Mullendore M, Buchholz M, Maitra A \& Feldmann G 2007 Snail and Sonic Hedgehog activation in neuroendocrine tumors of the ileum. Endocrine-Related Cancer 14 865-874. (https://doi.org/10.1677/ERC07-0108)

Fendrich V, Lopez CL, Manoharan J, Maschuw K, Wichmann S, Baier A Holler JP, Ramaswamy A, Bartsch DK \& Waldmann J 2014 Enalapril and ASS inhibit tumor growth in a transgenic mouse model of islet cell tumors. Endocrine-Related Cancer 21 813-824. (https://doi. org/10.1530/ERC-14-0175)

Funa K, Papanicolaou V, Juhlin C, Rastad J, Akerstrom G, Heldin CH \& Oberg K 1990 Expression of platelet-derived growth factor $\beta$-receptors on stromal tissue cells in human carcinoid tumors. Cancer Research 50 748-753.

Galvan JA, Astudillo A, Vallina A, Fonseca PJ, Gomez-Izquierdo L, Garcia-Carbonero R \& Gonzalez MV 2013 Epithelial-mesenchymal transition markers in the differential diagnosis of gastroenteropancreatic neuroendocrine tumors. American Journal of Clinical Pathology 140 61-72. (https://doi.org/10.1309/ AJCPIV40ISTBXRAX)

García-Suárez O, García B, Fernández-Vega I, Astudillo A \& Quirós LM 2014 Neuroendocrine tumors show altered expression of chondroitin sulfate, glypican 1 , glypican 5 , and syndecan 2 depending on their differentiation grade. Frontiers in Oncology 4 15. (https://doi. $\operatorname{org} / 10.3389 /$ fonc.2014.00015)

Grozinsky-Glasberg S, Shimon I \& Rubinfeld H 2012 The role of cell lines in the study of neuroendocrine tumors. Neuroendocrinology 96 173-187. (https://doi.org/10.1159/000338793)

Halperin DM, Shen C, Dasari A, Xu Y, Chu Y, Zhou S, Shih YT \& Yao JC 2017 Frequency of carcinoid syndrome at neuroendocrine tumour diagnosis: a population-based study. Lancet Oncology 18 525-534. (https://doi.org/10.1016/S1470-2045(17)30110-9)

Hauso Ø, Gustafsson BI, Loennechen JP, Stunes AK, Nordrum I \& Waldum HL 2007 Long-term serotonin effects in the rat are prevented by terguride. Regulatory Peptides 143 39-46. (https://doi. org/10.1016/j.regpep.2007.02.009)

Hellman P, Hessman O, Åkerström G, Stålberg P, Hennings J, Björck M \& Eriksson LG 2010 Stenting of the superior mesenteric vein in midgut carcinoid disease with large mesenteric masses. World Journal of Surgery 34 1373-1379. (https://doi.org/10.1007/s00268-009-0361-3)

Hobday TJ, Rubin J, Holen K, Picus J, Donehower R, Marschke R, Maples W, Lloyd R, Mahoney M \& Erlichman C 2007 MC044h, a phase II trial of sorafenib in patients (pts) with metastatic neuroendocrine tumors (NET): A Phase II Consortium (P2C) study. Journal of Clinical Oncology 25 4504. (https://doi.org/10.1200/ JCO.2007.12.3901)

Hoeft K \& Kramann R 2017 Developmental signaling and organ fibrosis Current Pathobiology Reports 5 133-143. (https://doi.org/10.1007/ s40139-017-0136-8)

Jacobson A \& Cunningham JL 2012 Connective tissue growth factor in tumor pathogenesis. Fibrogenesis and Tissue Repair 5 S8.

Jorissen RN, Walker F, Pouliot N, Garrett TPJ, Ward CW \& Burgess AW 2003 Epidermal growth factor receptor: mechanisms of activation and signalling. Experimental Cell Research 284 31-53. (https://doi. org/10.1016/S0014-4827(02)00098-8)

Kalluri R 2016 The biology and function of fibroblasts in cancer. Nature Reviews Cancer 16 582-598. (https://doi.org/10.1038/nrc.2016.73)

Kidd M, Eick GN, Modlin IM, Pfragner R, Champaneria MC \& Murren J $2007 a$ Further delineation of the continuous human neoplastic enterochromaffin cell line, KRJ-I, and the inhibitory effects of lanreotide and rapamycin. Journal of Molecular Endocrinology 38 181-192. (https://doi.org/10.1677/jme.1.02037)

Kidd M, Modlin IM, Pfragner R, Eick GN, Champaneria MC, Chan AK, Camp RL \& Mane SM 2007b Small bowel carcinoid (enterochromaffin cell) neoplasia exhibits transforming growth factor-beta1-mediated regulatory abnormalities including up-regulation of C-Myc and MTA1. Cancer 109 2420-2431. (https://doi.org/10.1002/cncr.22725)

Kidd M, Modlin IM, Shapiro MD, Camp RL, Mane SM, Usinger W \& Murren JR 2007c CTGF, intestinal stellate cells and carcinoid fibrogenesis. World Journal of Gastroenterology 13 5208-5216. (https://doi.org/10.3748/wjg.v13.i39.5208)

Koon HW, Shih D, Karagiannides I, Zhao D, Fazelbhoy Z, Hing T, Xu H, Lu B, Gerard N \& Pothoulakis C 2010 Substance P modulates colitisassociated fibrosis. American Journal of Pathology 177 2300-2309. (https://doi.org/10.2353/ajpath.2010.100314)

Krishnamurthy S \& Dayal Y 1997 Immunohistochemical expression of transforming growth factor alpha and epidermal growth factor receptor in gastrointestinal carcinoids. American Journal of Surgical Pathology 21 327-333. (https://doi.org/10.1097/00000478199703000-00009)

Kulke MH, Lenz H-J, Meropol NJ, Posey J, Ryan DP, Picus J, Bergsland E, Stuart K, Tye L, Huang X, et al. 2008 Activity of sunitinib in patients with advanced neuroendocrine tumors. Journal of Clinical Oncology 26 3403-3410. (https://doi.org/10.1200/ JCO.2007.15.9020)

Kulke MH, Horsch D, Caplin ME, Anthony LB, Bergsland E, Oberg K, Welin S, Warner RR, Lombard-Bohas C, Kunz PL, et al. 2017 Telotristat ethyl, a tryptophan hydroxylase inhibitor for the treatment of carcinoid syndrome. Journal of Clinical Oncology 35 14-23. (https://doi.org/10.1200/JCO.2016.69.2780)

Kunnimalaiyaan M, Traeger K \& Chen H 2005 Conservation of the Notch1 signaling pathway in gastrointestinal carcinoid cells. American Journal of Physiology: Gastrointestinal and Liver Physiology 289 G636-G642. (https://doi.org/10.1152/ajpgi.00146.2005)

Lang A, Sakhnini E, Fidder HH, Maor Y, Bar-Meir S \& Chowers Y 2005 Somatostatin inhibits pro-inflammatory cytokine secretion from rat hepatic stellate cells. Liver International 25 808-816. (https://doi. org/10.1111/j.1478-3231.2005.01057.x)

Leask A \& Abraham DJ 2006 All in the CCN family: essential matricellular signaling modulators emerge from the bunker. Journal of Cell Science 119 4803-4810. (https://doi.org/10.1242/jcs.03270)

Linan-Rico A, Ochoa-Cortes F, Beyder A, Soghomonyan S, ZuletaAlarcon A, Coppola V \& Christofi FL 2016 Mechanosensory signaling in enterochromaffin cells and 5-HT release: potential implications for gut inflammation. Frontiers in Neuroscience 10564. (https://doi.org/10.3389/fnins.2016.00564)

Makridis C, Oberg K, Juhlin C, Rastad J, Johansson H, Lorelius LE \& Akerstrom G 1990 Surgical treatment of mid-gut carcinoid tumors. World Journal of Surgery 14 377-383; discussion 384-375. (https://doi. org/10.1007/BF01658532)

Mann DA \& Oakley F 2013 Serotonin paracrine signaling in tissue fibrosis. Biochimica et Biophysica Acta: Molecular Basis of Disease 1832 905-910. (https://doi.org/10.1016/j.bbadis.2012.09.009)

Mantovani A, Allavena P, Sica A \& Balkwill F 2008 Cancer-related inflammation. Nature $\mathbf{4 5 4} 436-444$. (https://doi.org/10.1038/ nature07205)

Massague J 2012 TGFbeta signalling in context. Nature Reviews Molecular Cell Biology 13 616-630. (https://doi.org/10.1038/nrm3434)

Mikulec AA, Hanasono MM, Lum J, Kadleck JM, Kita M \& Koch R 2001 Effect of tamoxifen on transforming growth factor $\beta 1$ production by keloid and fetal fibroblasts. Archives of Facial Plastic Surgery 3 111-114. (https://doi.org/10.1001/archfaci.3.2.111)

Modlin IM, Shapiro MD \& Kidd M 2004 Carcinoid tumors and fibrosis: an association with no explanation. American Journal of
2018 Society for Endocrinology Published by Bioscientifica Ltd. Printed in Great Britain 
Gastroenterology 99 2466-2478. (https://doi. org/10.1111/j.1572-0241.2004.40507.x)

Modlin IM, Pavel M, Kidd M \& Gustafsson BI 2010 Review article: somatostatin analogues in the treatment of gastroenteropancreatic neuroendocrine (carcinoid) tumours. Alimentary Pharmacology and Therapeutics 31 169-188. (https://doi. org/10.1111/j.1365-2036.2009.04174.x)

Moertel CG, Engstrom PF \& Schutt AJ 1984 Tamoxifen therapy for metastatic carcinoid tumor: a negative study. Annals of Internal Medicine 100 531-532. (https://doi.org/10.7326/0003-4819-100-4531)

Moertel CG, Kvols LK \& Rubin J 1991 A study of cyproheptadine in the treatment of metastatic carcinoid tumor and the malignant carcinoid syndrome. Cancer 67 33-36. (https://doi.org/10.1002/10970142(19910101)67:1<33::AID-CNCR2820670107>3.0.CO;2-E)

Mohammad-Zadeh LF, Moses L \& Gwaltney-Brant SM 2008 Serotonin: a review. Journal of Veterinary Pharmacology and Therapeutics $\mathbf{3 1}$ 187-199. (https://doi.org/10.1111/j.1365-2885.2008.00944.x)

Murphy AM, Wong AL \& Bezuhly M 2015 Modulation of angiotensin II signaling in the prevention of fibrosis. Fibrogenesis and Tissue Repair 87

Myers CF, Ershler WB, Tannenbaum MA \& Barth R 1982 Tamoxifen and carcinoid tumor. Annals of Internal Medicine 96 383. (https://doi. org/10.7326/0003-4819-96-3-383_1)

Nakakura EK, Sriuranpong VR, Kunnimalaiyaan M, Hsiao EC, Schuebel KE, Borges MW, Jin N, Collins BJ, Nelkin BD, Chen H, et al. 2005 Regulation of neuroendocrine differentiation in gastrointestinal carcinoid tumor cells by notch signaling. Journal of Clinical Endocrinology and Metabolism 90 4350-4356. (https://doi. org/10.1210/jc.2005-0540)

Niederle B, Pape UF, Costa F, Gross D, Kelestimur F, Knigge U, Oberg K, Pavel M, Perren A, Toumpanakis C, et al. 2016 ENETS Consensus Guidelines update for neuroendocrine neoplasms of the jejunum and ileum. Neuroendocrinology 103 125-138. (https://doi. org/10.1159/000443170)

Nilsson O, Wangberg B, McRae A, Dahlstrom A \& Ahlman H 1993 Growth factors and carcinoid tumours. Acta Oncologica 32 115-124. (https://doi.org/10.3109/02841869309083899)

Nilsson O, Wängberg B, Kölby L, Schultz GS \& Ahlman H 1995 Expression of transforming growth factor alpha and its receptor in human neuroendocrine tumours. International Journal of Cancer $\mathbf{6 0}$ 645-651. (https://doi.org/10.1002/ijc.2910600514)

Nishizawa H, Iguchi G, Fukuoka H, Takahashi M, Suda K, Bando H, Matsumoto R, Yoshida K, Odake Y, Ogawa W, et al. 2016 IGF-I induces senescence of hepatic stellate cells and limits fibrosis in a p53-dependent manner. Scientific Reports 6 34605. (https://doi. org/10.1038/srep34605)

Nowell CS \& Radtke F 2017 Notch as a tumour suppressor. Nature Reviews Cancer 17 145-159. (https://doi.org/10.1038/nrc.2016.145)

Öhrvall U, Eriksson B, Juhlin C, Karacagil S, Rastad J, Hellman P \& Åkerström G 2000 Method for dissection of mesenteric metastases in mid-gut carcinoid tumors. World Journal of Surgery 24 1402-1408. (https://doi.org/10.1007/s002680010232)

Pantongrag-Brown L, Buetow PC, Carr NJ, Lichtenstein JE \& Buck JL 1995 Calcification and fibrosis in mesenteric carcinoid tumor: CT findings and pathologic correlation. American Journal of Roentgenology 164 387-391. (https://doi.org/10.2214/ajr.164.2.7839976)

Pavel M, O'Toole D, Costa F, Capdevila J, Gross D, Kianmanesh R, Krenning E, Knigge U, Salazar R, Pape UF, et al. 2016 ENETS Consensus Guidelines update for the management of distant metastatic disease of intestinal, pancreatic, bronchial neuroendocrine neoplasms (NEN) and NEN of unknown primary site. Neuroendocrinology 103 172-185. (https://doi.org/10.1159/000443167)

Phan AT, Yao JC, Fogelman DR, Hess KR, Ng CS, Bullock SA, Malinowski P, Regan E \& Kulke M 2010 A prospective, multiinstitutional phase II study of GW786034 (pazopanib) and depot octreotide (sandostatin LAR) in advanced low-grade neuroendocrine carcinoma (LGNEC). Journal of Clinical Oncology 28 4001-4001. (https://doi.org/10.1200/jco.2010.28.15_suppl.4001)

Pietras K \& Hanahan D 2005 A multitargeted, metronomic, and maximum-tolerated dose 'chemo-switch' regimen is antiangiogenic, producing objective responses and survival benefit in a mouse model of cancer. Journal of Clinical Oncology 23 939-952. (https://doi. org/10.1200/JCO.2005.07.093)

Pollak MN, Schernhammer ES \& Hankinson SE 2004 Insulin-like growth factors and neoplasia. Nature Reviews Cancer 4 505-518. (https://doi. org/10.1038/nrc1387)

Quail DF \& Joyce JA 2013 Microenvironmental regulation of tumor progression and metastasis. Nature Medicine 19 1423-1437. (https://doi.org/10.1038/nm.3394)

Robertson JIS 1990 Carcinoid syndrome and serotonin: Therapeutic effects of ketanserin. Cardiovascular Drugs and Therapy 4 53-58. (https://doi.org/10.1007/BF00053427)

Rodriguez Laval V, Pavel M, Steffen IG, Baur AD, Dilz LM, Fischer C, Detjen K, Prasad V, Pascher A, Geisel D, et al. 2017 Mesenteric fibrosis in midgut neuroendocrine tumors: functionality and radiological features. Neuroendocrinology [epub]. (https://doi. org/10.1159/000474941)

Rybinski B, Franco-Barraza J \& Cukierman E 2014 The wound healing, chronic fibrosis, and cancer progression triad. Physiological Genomics 46 223-244. (https://doi.org/10.1152/physiolgenomics.00158.2013)

Sandler M \& Close HG 1959 Biochemical effect of phenylacetic acid in a patient with 5-hydroxytryptophan-secreting carcinoid tumor. Lancet 2 316-318. (https://doi.org/10.1016/S0140-6736(59)91358-3)

Shah T, Hochhauser D, Frow R, Quaglia A, Dhillon AP \& Caplin ME 2006 Epidermal growth factor receptor expression and activation in neuroendocrine tumours. Journal of Neuroendocrinology 18 355-360. (https://doi.org/10.1111/j.1365-2826.2006.01425.x)

Siddique ZL, Drozdov I, Floch J, Gustafsson BI, Stunes K, Pfragner R, Kidd M \& Modlin IM 2009 KRJ-I and BON cell lines: defining an appropriate enterochromaffin cell neuroendocrine tumor model. Neuroendocrinology 89 458-470. (https://doi.org/10.1159/000209330)

Sjoerdsma A, Oates JA, Zaltzman P \& Udenfriend S 1960 Serotonin synthesis in carcinoid patients. New England Journal of Medicine 263 585-588. (https://doi.org/10.1056/NEJM196009222631204)

Stathopoulos GP, Karvountzis GG \& Yiotis J 1981 Tamoxifen in carcinoid syndrome. New England Journal of Medicine 30552 (https://doi.org/10.1056/nejm198107023050114)

Svejda B, Kidd M, Giovinazzo F, Eltawil K, Gustafsson BI, Pfragner R \& Modlin IM 2010 The 5-HT2B receptor plays a key regulatory role in both neuroendocrine tumor cell proliferation and the modulation of the fibroblast component of the neoplastic microenvironment. Cancer 116 2902-2912. (https://doi.org/10.1002/cncr.25049)

Turner N \& Grose R 2010 Fibroblast growth factor signalling: from development to cancer. Nature Reviews Cancer 10 116-129. (https://doi.org/10.1038/nrc2780)

van Bommel EH, Hendriksz TR, Huiskes AC \& Zeegers AM 2006 Brief communication: tamoxifen therapy for nonmalignant retroperitoneal fibrosis. Annals of Internal Medicine 144 101-106. (https://doi.org/10.7326/0003-4819-144-2-200601170-00007)

Vettori S, Gay S \& Distler O 2012 Role of microRNAs in fibrosis. Open Rheumatology Journal 6 130-139. (https://doi.org/10.2174/187431290 1206010130)

Vinik AI, Gonin J, England BG, Jackson T, McLeod MK \& Cho K 1990 Plasma substance-P in neuroendocrine tumors and idiopathic flushing: the value of pentagastrin stimulation tests and the effects of somatostatin analog. Journal of Clinical Endocrinology and Metabolism 70 1702-1709. (https://doi. org/10.1210/jcem-70-6-1702)

Vizza D, Perri A, Toteda G, Lupinacci S, Leone F, Gigliotti P, Lofaro D, La Russa A \& Bonofiglio R 2015 Nerve growth factor exposure promotes tubular epithelial-mesenchymal transition via TGF-beta1 signaling
2018 Society for Endocrinology Published by Bioscientifica Ltd. Printed in Great Britain 
activation. Growth Factors 33 169-180. (https://doi.org/10.3109/0897 7194.2015.1054989)

von Wichert G, Jehle PM, Hoeflich A, Koschnick S, Dralle H, Wolf E, Wiedenmann B, Boehm BO, Adler G \& Seufferlein T 2000 Insulinlike growth factor-I is an autocrine regulator of chromogranin A secretion and growth in human neuroendocrine tumor cells. Cancer Research 60 4573-4581.

Wan Y, Meng F, Wu N, Zhou T, Venter J, Francis H, Kennedy L, Glaser T, Bernuzzi F, Invernizzi P, et al. 2017 Substance P increases liver fibrosis by differential changes in senescence of cholangiocytes and hepatic stellate cells. Hepatology 66 528-541. (https://doi. org/10.1002/hep.29138)

Wang H, Chen Y, Fernandez-Del Castillo C, Yilmaz O \& Deshpande V 2013 Heterogeneity in signaling pathways of gastroenteropancreatic neuroendocrine tumors: a critical look at notch signaling pathway. Modern Pathology 26 139-147. (https://doi.org/10.1038/ modpathol.2012.143)

Wimmel A, Wiedenmann B \& Rosewicz S 2003 Autocrine growth inhibition by transforming growth factor beta-1 (TGFbeta-1) in human neuroendocrine tumour cells. Gut 52 1308-1316. (https://doi.org/10.1136/gut.52.9.1308)

Witsch E, Sela M \& Yarden Y 2010 Roles for growth factors in cancer progression. Physiology 25 85-101. (https://doi.org/10.1152/ physiol.00045.2009)

Wulbrand U, Wied M, Zofel P, Goke B, Arnold R \& Fehmann H 1998 Growth factor receptor expression in human gastroenteropancreatic neuroendocrine tumours. European Journal of Clinical Investigation $\mathbf{2 8}$ 1038-1049. (https://doi.org/10.1046/j.1365-2362.1998.00397.x)
Wulbrand U, Remmert G, Zöfel P, Wied M, Arnold R \& Fehmann HC 2000 mRNA expression patterns of insulin-like growth factor system components in human neuroendocrine tumours. European Journal of Clinical Investigation 30 729-739. (https://doi. org/10.1046/j.1365-2362.2000.00700.x)

Wynn TA 2008 Cellular and molecular mechanisms of fibrosis. Journal of Pathology 214 199-210. (https://doi.org/10.1002/path.2277)

Yang K, Ulich T, Cheng L \& Lewin KJ 1983 The neuroendocrine products of intestinal carcinoids. An immunoperoxidase study of 35 carcinoid tumors stained for serotonin and eight polypeptide hormones. Cancer 51 1918-1926. (https://doi.org/10.1002/10970142(19830515)51:10<1918::AID-CNCR2820511027>3.0.CO;2-Y)

Yao JC, Hassan M, Phan A, Dagohoy C, Leary C, Mares JE, Abdalla EK, Fleming JB, Vauthey JN, Rashid A, et al. 2008 One hundred years after 'carcinoid': epidemiology of and prognostic factors for neuroendocrine tumors in 35,825 cases in the United States. Journal of Clinical Oncology 26 3063-3072. (https://doi.org/10.1200/ JCO.2007.15.4377)

Zandee WT, Kamp K, van Adrichem RC, Feelders RA \& de Herder WW 2016 Limited value for urinary 5-HIAA excretion as prognostic marker in gastrointestinal neuroendocrine tumours. European Journal of Endocrinology 175 361-366. (https://doi.org/10.1530/ EJE-16-0392)

Zhang PJ, Furth EE, Cai X, Goldblum JR, Pasha TL \& Min KW 2004 The role of $\beta$-catenin, TGF $\beta 3$, NGF2, FGF2, IGFR2, and BMP4 in the pathogenesis of mesenteric sclerosis and angiopathy in midgut carcinoids. Human Pathology 35 670-674. (https://doi.org/10.1016/j. humpath.2003.12.010)

Received in final form 15 November 2017

Accepted 12 December 2017

Accepted Preprint published online 12 December 2017 (c) 2018 Society for Endocrinology Published by Bioscientifica Ltd. Printed in Great Britain 